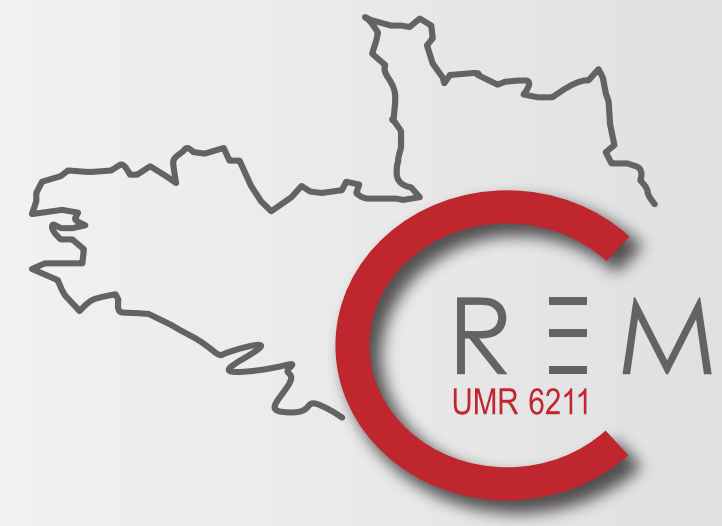

Centre de Recherche en Économie et Management Center for Research in Economics and Management
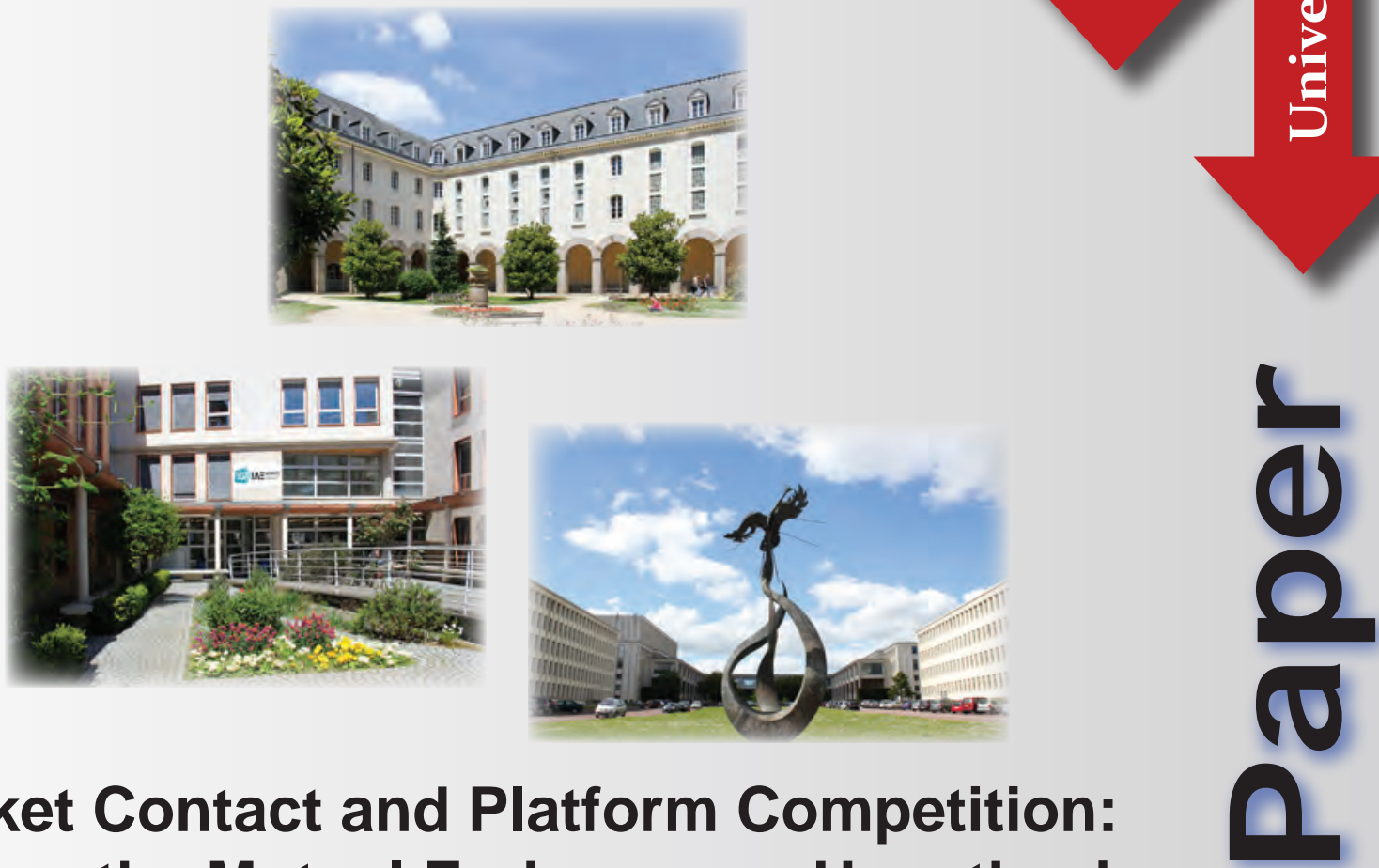

Multimarket Contact and Platform Competition: Reassessing the Mutual Forbearance Hypothesis

\title{
Éric Darmon
}

Univ Rennes, CNRS, CREM UMR 6211, F-35000 Rennes, France

\section{Thomas Le Texier}

Univ Rennes, CNRS, CREM UMR 6211, F-35000 Rennes, France

\section{Zhiwen Li}

School of Management, Jiangsu University, China

\section{Thierry Pénard}

Univ Rennes, CNRS, CREM UMR 6211, F-35000 Rennes, France

Septembre 2019 - WP 2019-07 


\title{
Multimarket Contact and Platform Competition: Reassessing the Mutual Forbearance Hypothesis
}

\author{
Eric DARMON*, Thomas LE TEXIER ${ }^{\dagger}$ \\ Zhiwen LI $^{\ddagger}$ and Thierry PENARD ${ }^{\S}$
}

August 30th, 2019

\begin{abstract}
Antitrust authorities are particularly conc and with the dominant market position of tech giants such as Google, Facebook, and Amazc $=$ These digital conglomerates are characterized by platform-based business models. However, despite their dominance, they are competing with each other to attract the same groups of users (developers, advertisers, end users, third party sellers, etc). They therefore have not only overlapping users (or sides) but also multimarket contact (MMC). In traditional one-sided markets, theory and empirical evidence show that MMC tends to relax competition. However, it is unclear whether this result holds under platform competition. This paper examines how MMC affects pricing behaviour and profits of two-sided platforms. We develop a model of platform competition with two distinct markets. We assume that platforms only charge one group of users and provide free access to the other group. We argue that multimarket platforms also generate cross-market externalities that favour their users, in addition to well-known cross-group externalities. We find that when cross-market externalities benefit the side that has free access, price competition is fiercer and total welfare increases under MMC. However, when they benefit the side that pays to access the platform, the same result only holds if the cross-group externality and/or cross-market externality are sufficiently high. Finally, we show that a single-market platform competing with a multimarket platform may be deterred from entering the second market if cross-market or cross-group externalities are high. Our findings contrast with the mutual forbearance hypothesis which claims that MMC relaxes competition in traditional (one-sided) industries. From a competition policy perspective, our paper provides an insight into how antitrust authorities should review conglomerate mergers and assess the effects of diversification strategies of digital platforms.

Keywords: two-sided markets, platform competition, multimarket contact, conglomerate, digital markets
\end{abstract}

JEL Codes: L13, L49, L86

\footnotetext{
*Univ Rennes, CNRS, CREM (Centre de Recherche en Economie et Management) - UMR 6211, F-35000 Rennes, France, E-mail: eric.darmon@univ-rennes1.fr

${ }^{\dagger}$ Univ Rennes, CNRS, CREM (Centre de Recherche en Economie et Management) - UMR 6211, F-35000 Rennes, France, E-mail: thomas.letexier@univ-rennes1.fr

¥School of Management, Jiangsu University, China, E-mail: zhiwenli@mail.ujs.edu.cn

$\S$ Univ Rennes, CNRS, CREM (Centre de Recherche en Economie et Management) - UMR 6211, F-35000 Rennes, France, E-mail: thierry.penard@univ-rennes1.fr
} 


\section{Introduction}

The market dominance of Google, Apple, Facebook and Amazon (GAFA) poses a big challenge for antitrust authorities ( Evans and Schmalensee (2013), Filistrucchi and Klein (2013), Peitz and Valletti (2015), Cremer et al. (2019)). These tech companies have monopolized many digital markets, by taking advantage of network effects and massive data collection. Their expansion relies on internal and external (mergers \& acquisitions) growth strategies that strengthen their position in their core markets. They have also achieved a high level of diversification, not only by penetrating complementary markets, but also unrelated markets (Bourreau and De Streel (2019)). For instance, while the initial market of Google is search engines, it has also diversified into operating systems, video/music streaming services, cloud services, voice assistance, etc. Amazon also offers a conglomerate of products, ranging from e-commerce to payment services, cloud computing, electronic devices and video services. Although these conglomerate strategies generate synergies (network effects, data sharing, etc), they may reinforce GAFA dominance and create insurmountable barriers to entry.

In this context, the purchase of WhatsApp by Facebook bought in 2014 for $\$ 19$ billion was highly debated. The European Commission (EC) eventually approved the deal based on the argument that the two platforms were not operating in the same market: Facebook is a social networking service whereas WhatsApp is a communication service. According to the EC, "consumers would continue to have a wide choice of alternative communications apps after the transaction [and] the merged entity would continue to face sufficient competition after the merger.(...) Furthermore, even in the event of an integration between WhatsApp and Facebook such that Facebook's position in social networking services could be strengthened, the net gain in terms of new members of the social network would be limited, since the user base of WhatsApp already overlaps to a significant extent

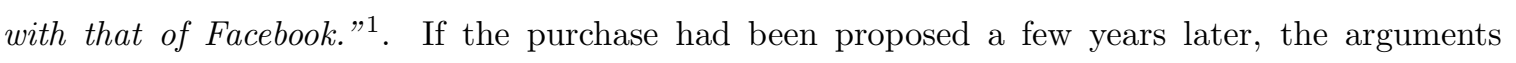
and the decision of the EC would probably have been different, given the increasing domination of Facebook in social networking, together with increased calls from politicians and citizens for greater regulation of these tech giants. In recent years, the regulation of digital markets has been investigated by competition authorities both in the United States ( Scott Morton et al. (2019)) and

\footnotetext{
${ }^{1}$ European Commission Press Release no. IP/14/1088, released on 3 October 2014, available from http://europa.eu/rapid/press-release_IP-14-1088_en.htm
} 
in the European Union (Cremer et al. (2019)). Several antitrust scholars have argued that there is a need for more stringent merger controls and structural remedies to the GAFA (Shapiro (2019)). In their defence, tech companies claim that they are struggling to attract and retain the same groups of users (advertisers, developers, third party sellers, end users, etc), and there is anecdotal evidence of numerous market overlaps between them. For instance, Google, Facebook, Apple, Microsoft and Amazon are competing with each other in multiple markets, including cloud computing \& storage, streaming services, voice \& video calling, and payment wallets. ${ }^{2}$ According to Evans (2017), such multimarket contact (MMC) is evidence of intense competition in digital markets. However a large body of theoretical and empirical literature shows that MMC creates mutual forbearance (Edwards (1955)) and reduces rivalry among firms. At the same time, such findings apply to the context of traditional one-sided industries while most digital services are provided by or through two-sided platforms (Rochet and Tirole (2003)). The effects of MMC in two sided markets appear to be unexplored. The aim of our article is to fill this gap and better understand how platforms compete in the presence of MMC. From a competition policy perspective, does increased MMC between conglomerates such as Google, Facebook or Apple increase or relax competition in digital markets?

To answer this question, we develop a model of platform competition in two markets. In each of the two markets, there are two platforms that need to attract two groups (sides) of users: for example, sellers and buyers in the context of a marketplace, developers and end users in the context of an application store, passengers and drivers in the context of a ride-hailing platform. We assume that only one side pays to join the platform (i.e. the other side has free access), as this is, in practice, the most common pricing model of two-sided platforms and will simplify the computation of prices and profits. When a company operates a platform in both of the two markets, we define it as a multimarket platform. Without loss of generality, we assume that the company uses the same brandname for its platform in both markets. However, the model does not change if the company uses distinct names in each market as long as the two platforms are technically connected. MMC occurs when multimarket platforms compete with each other. The key assumption is that a multimarket platform generates positive externalities (or spillovers) across markets that may benefit the platform's users. In digital markets, these cross-market externalities are mainly data-driven.

\footnotetext{
${ }^{2}$ See Table 3 in Evans (2017) for other examples.
} 
A company that integrates or connects two platforms (e.g. Facebook and Instagram) can collect and share data about the users of both platforms. Through data sharing, a multimarket platform can improve its recommendations, targeting, search or matching tools which increases the utility of its users in all markets. The more users (and user data) that are gathered, the more attractive the platform becomes in every market. A multimarket platform can also provide more innovative services, expand product variety and audience reach, and increase interoperability between devices that are used to access it. For instance, Li and Agarwal (2017) found that the acquisition of Instagram and its integration in the Facebook ecosystem added value not only for consumers, but also for Facebook application developers. To better understand and disentangle the effects of these cross-market externalities, we consider two settings: i) cross-market externalities only benefit the group of users that pay to access the platform; and ii) cross-market externalities only benefit the non-paying group. In both settings, we fully characterize the outcome of platform competition with, and without MMC. Two kinds of effects emerge in this competition framework. The first are caused by cross-group externalities. In every market, the utility of platform users depends, positively, on the number of users on the other side of the platform. In addition to these intramarket effects, cross-market effects are also found on multimarket platforms, such that the utility of users in one market increases with the number of users on the other side of the platform in the second market.These demand-side cross-market spillovers reinforce the attractiveness of the platform in all markets. ${ }^{3}$ We find that when cross-market externalities benefit the side that has free access, price competition is fiercer and welfare increases under MMC. When cross-market externalities benefit the paying side, the same result only holds if cross-group externalities and/or cross-market externalities are sufficiently high. Finally, we show that a single-market platform competing with a multimarket platform has no incentive to adopt a multimarket strategy if cross-market and crossgroup externalities are both high. Our findings contrast with the mutual forbearance hypothesis which claims that MMC relaxes competition/rivalry in traditional industries. In most cases, price competition is fiercer and welfare increases under MMC. From a competition policy perspective, our paper provides an insight into how antitrust authorities should review conglomerate mergers and

\footnotetext{
${ }^{3}$ Cross-market effects can appear whether the multimarket platform uses the same brandname in all markets or operates under distinct names (e.g. for Uber, Uber Eats in the food delivery market and UberX on the ride-hailing market, or for Google, GooglePlayStore in the application store market and YouTube on the video streaming market).
} 
assess the effects of diversification strategies of digital platforms. Specifically, when they examine the integration of two platforms that are in different markets, they should focus on who will benefit from cross-market externalities. When the latter benefit non-paying users, there is little reason for concern. However if cross-market externalities benefit paying users, they should assess the magnitude of cross-group and cross market externalities before challenging such mergers and acquisitions.

Our paper builds on two strands of literature. The first is the literature on the effects of MMC. The two seminal papers are Edwards (1955) and Bernheim and Whinston (1990). Bernheim and Whinston (1990) examine the effect of MMC on firms' ability to increase their price. They show that MMC enables firms to transfer their ability to collude from highly collusive to weakly collusive markets. Firms recognize that a competitive attack in any one market may draw a response(s) in all jointly contested markets, reducing the incentive to behave aggressively (the mutual forbearance hypothesis). Empirical evidence has largely supported this hypothesis, for instance in the airline (Evans and Kessides (1994); Prince and Simon (2009)), telecommunication (Busse (2000); Parker and Roller (1997)) or hotel (Marin and Fernandez (1998)) industries. Similarly, Phillips and Mason (1992) provide experimental evidence that MMC increases cooperation. However, to the best of our knowledge, no study has examined the impact of MMC on two-sided markets, and how it affects access pricing and market share of platforms.

The second strand of literature concerns platform competition and mergers. This literature is both theoretical and empirical. Several papers analyze pricing behavior under platform competition (Rochet and Tirole (2003), Rochet and Tirole (2006), Caillaud and Jullien (2003), Belleflamme and Peitz (2019), Cabral et al. (2019)). For instance, Cabral et al. (2019) analyse how multi-homing on one side of a platform can affect pricing and whether it benefits or harms each side of the platform. Other papers focus on the effect of mergers between two-sided platforms (Correia-da Silva et al. (2019), Evans and Noel (2008)). Compared to the one-sided case, two-sided platform mergers have less anti-competitive effect, because consumers are more price sensitive (Behringer and Filistrucchi (2015)). There are also some empirical studies that have measured the effects of mergers in two-sided markets. For instance, Filistrucchi et al. (2012) study the effect of the merger of newspapers on their advertising revenues and prices paid by readers. 
The remainder of the article is organized as follows. Section 2 presents the theoretical framework and assumptions. Section 3 analyses the effect of MMC on platform competition. Section 4 considers incentives for a single-market platform that competes against multimarket platforms to become a multimarket platform. Section 5 concludes and discusses policy implications.

\section{The model}

We consider two distinct markets (market 1 and market 2). In each market, there are two platforms that compete à la Armstrong (2006). We compare the no MMC case (i.e. single-market platforms) to the MMC case (i.e. two multimarket platforms that compete simultaneously in the two markets).

\section{$2.1 \quad$ No MMC case}

Each platform gathers two groups of users (sides) and as conventional in this literature (Armstrong (2006)), we assume that there are positive externalities between the two sides (i.e. cross-group externality). Without loss of generality, let us denote the first group as sellers and the second group as buyers. For instance, in the case of an e-commerce marketplace, sellers could refer to merchants and buyers to final consumers. Another example is an application store platform that connects app developers (i.e. sellers in our model) to end users (buyers in our model). Let $J i$ be Firm $J$ $(J=\{A, B\})$ in market $i(i=\{1,2\})$. We denote by $n_{b, J i}$ (resp. $\left.n_{s, J i}\right)$ the number of active buyers (resp. sellers) on Platform $J$ in market $i$.

In each market, buyers have heterogeneous preferences and are uniformly distributed on a Hotelling line with $x$ denoting buyer location $(x \in[0,1])$. Platforms are horizontally differentiated with one platform located at 0 and the other at 1 . Buyers are single homing (i.e. they only use one of the two competing platforms) and incur no access fees. We also assume that the market is fully covered on the buyers' side.

Let $v(v>0)$ denote the intrinsic value that buyers derive from using the platform, while $t_{b} d$ $\left(t_{b}>0\right)$ denotes the disutility (or transportation cost) incurred by a buyer who is located at a distance $d$ from the platform. Parameter $\alpha_{s}$ denotes the marginal utility that buyers derive from an additional seller being present on the other side of the platform (i.e. the value of a cross-group externality for buyers). For instance, in the case of e-commerce platforms, buyers' utility increases 
with the number of merchants on the other side due to greater product variety and competition.

Thus, the utility that a $x$-type buyer derives from Platforms $A i$ and $B i$ can be expressed as follows:

$$
\text { market i }(i=\{1,2\})\left\{\begin{array}{l}
U_{A i}(x)=v-t_{b} x+\alpha_{s} n_{s, A i} \\
U_{B i}(x)=v-t_{b}(1-x)+\alpha_{s} n_{s, B i}
\end{array}\right.
$$

On the seller side, we assume that sellers are heterogeneous with respect to platform-specific setup costs (e.g. entry, development and customization costs) with $y$ denoting the parameter of heterogeneity $(0<y<1)$. Thus, a seller of type $y$ will incur a cost, $t_{s} y$, to join the platform. ${ }^{4}$ We also assume that only sellers are charged to access the platform (a price $p_{J i}$ ).

Let $\alpha_{b}\left(\alpha_{b}>0\right)$ be the marginal benefit that sellers derive from an additional buyer on the other side of the platform (i.e. the value of cross-group externality for sellers). In the case of, for example, an e-commerce platform, this parameter can be interpreted as the average expected revenue per shopper. In the case of an application store, it refers to the value extracted from a user (e.g. the value generated from users' purchases of apps - and in-app purchases). Hence $\alpha_{b} n_{s, J i}$ depicts the revenue of a seller that joins Platform $J$ in market $i$. Thus, the profit of a $y$-type seller can be expressed as follows:

$$
\pi_{J i}(y)=\alpha_{b} n_{b, J i}-t_{s} y-p_{J i}
$$

Note that in the no MMC case, there is no interaction between markets 1 and 2.

\subsection{With MMC case}

MMC results from competition between two multimarket platforms (i.e. when the platform owners is present in the two markets). Competition between multimarket Platforms $\mathrm{A}$ and $\mathrm{B}$ in market 1 and market 2 is illustrated in Figure 1.

\section{no-MMC}

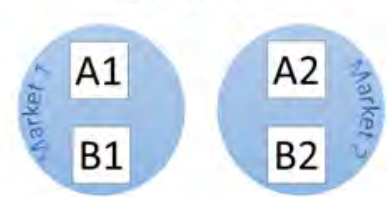

MMC

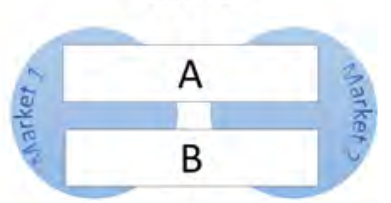

Figure 1: Comparison of market structures with and without MMC.

\footnotetext{
${ }^{4}$ Since this setup cost is platform-specific, a given seller could incur different (and uncorrelated) costs when joining distinct platforms. Without loss of generality, we consider that a seller enjoys no economies of scope (or diseconomies) when joining several platforms. Hence, whether sellers are single-homing or multi-homing is irrelevant to the outcome of the model.
} 
In addition to cross-group externality within each market, a multimarket platform generates cross-market externalities. We consider two sources of cross-market externality. First, sellers in a given market (say market 1) that join a multimarket platform may benefit from being connected directly or indirectly to the buyers enrolled by the platform in market 2. Hence, the platform can collect data on buyers in market 2 and share it with sellers in market 1 to help them reach new consumers or better served their current consumers. For instance consider a multimarket platform that provids food delivery and ride-hailing services. The platform can collect data about its users' trip habits (and location) and reuse it to improve the tools and services provided to the affiliated restaurants to help them advertise their menus and target potential customers. Restaurants benefit from joining a food delivery platform that has a lot of users on the other side, but also has plenty of users on other platforms that are part of the same ecosystem. Formally, when a seller joins a platform, its profit increases both with the number of buyers on the other side and on the other platforms operated by the same company, as this generates buyer-driven cross-market externalities that benefit all sellers. These externalities are measured by the parameter $\gamma_{b}\left(\gamma_{b}>0\right)$.

Similarly, buyers that join a multimarket platform in a specific market may benefit from the presence of sellers in another market. For instance, gains can be derived from increased interoperability between the services provided by sellers in both markets through better API and platform integration ${ }^{5}$. In the case of Google Play Store and Google Home, many third-party applications are available on both platforms. End users may join the Google ecosystem because they want to synchronize their data and usage related to these third-party applications. Improved combinations of services can lead to the provision of innovative services through mash-up and customization of multiple applications and tools. This seller-driven cross-market externality is measured by parameter $\gamma_{s}\left(\gamma_{s}>0\right)$ multiplied by the number of sellers on the other market.

Utility and profit can thus be rewritten as follows in the MMC case. ${ }^{6}$

$$
\operatorname{market~} i(i=\{1,2\})\left\{\begin{array}{l}
U_{A i}(x)=v-t_{b} x+\alpha_{s} n_{s, A i}+\gamma_{\mathbf{s}} \mathbf{n}_{\mathbf{s}, \mathbf{A}-\mathbf{i}} \\
U_{B i}(x)=v-t_{b}(1-x)+\alpha_{s} n_{s, B i}+\gamma_{\mathbf{s}} \mathbf{n}_{\mathbf{s}, \mathbf{B}-\mathbf{i}} \\
\pi_{A i}(y)=\alpha_{b} n_{s, A i}-t_{s} y-p_{A i}+\gamma_{\mathbf{b}} \mathbf{n}_{\mathbf{b}, \mathbf{A}-\mathbf{i}} \\
\pi_{B i}(y)=\alpha_{b} n_{s, B i}-t_{s} y-p_{B i}+\gamma_{\mathbf{b}} \mathbf{n}_{\mathbf{b}, \mathbf{B}-\mathbf{i}}
\end{array}\right.
$$

We need to set some conditions/restrictions on parameters to find equilibria in which the two

\footnotetext{
${ }^{5}$ APIs (Application Programming Interface) enable information transfer from one service to another)

${ }^{6}$ Differences with the no MMC case are indicated in bold characters.
} 
rival platforms are active (i.e. equilibria with interior solutions). We consider two cases: i) crossmarket externalities only benefit buyers $\left(\gamma_{s}>0, \gamma_{b}=0\right)$ and ii) cross-market externalities only benefit sellers $\left(\gamma_{s}=0, \gamma_{b}>0\right)$. In the first case, the externality benefits the side that has free access to the platform whereas in the second case, it benefits the side that pays for access. These two extreme cases provide a better understanding of the effects of cross-market externalities on platform competition and highlight how these effects are highly dependent on which side of the platform gets additional value from multimarket synergies.

In both cases, we have to assume that transportation cost parameters $t_{b}$ and $t_{s}$ are sufficiently large compared to cross-group parameters $\alpha_{b}$ and $\alpha_{s}$. Formally, we assume that $t_{b} t_{s}>\alpha_{b} \alpha_{s}$. Note that such a specification for parameters $t_{b}, t_{s}, \alpha_{b}$ and $\alpha_{s}$ is standard when studying competition in two-sided markets, and can be found in Armstrong (2006) or Belleflamme and Peitz (2019), for instance. We also assume that cross-market externality parameters $\gamma_{k}(k=b, s)$ are upper-bounded, so that at equilibrium; (i) buyers' demand is fully-covered; (ii) some sellers are active; and (iii) profit-maximizing access prices are positive.

Formally, when MMC only generates a seller-driven cross-market externality (i.e. $\gamma_{b}=0$ ), the cross-market externality parameter $\gamma_{s}$ must satisfy $t_{b} t_{s}-\alpha_{b} \alpha_{s}>\gamma_{s} \alpha_{b}$. Similarly, when MMC only drives a buyer-driven cross-market externality (i.e. $\gamma_{s}=0$ ), the cross-market externality parameter $\gamma_{b}$ must satisfy $t_{b} t_{s}-\alpha_{b} \alpha_{s}>\gamma_{b} \alpha_{s}$. Assumptions 1 and 2 sum up these conditions.

Assumption 1 In the two-sided platform competition setting where MMC only generates a sellerdriven cross-market externality $\left(\gamma_{b}=0\right)$, parameters satisfy $t_{b} t_{s}>\alpha_{b} \alpha_{s}$ and $t_{b} t_{s}-\alpha_{b} \alpha_{s}>\gamma_{s} \alpha_{b}$.

Assumption 2 In the two-sided platform competition setting where MMC only generates a buyerdriven cross-market externality $\left(\gamma_{s}=0\right)$, parameters satisfy $t_{b} t_{s}>\alpha_{b} \alpha_{s}$ and $t_{b} t_{s}-\alpha_{b} \alpha_{s}>\gamma_{b} \alpha_{s}$.

\subsection{Platform strategy and timing of the game}

Competition between platforms is a two-step game. In Step 1, platforms simultaneously choose the access price charged to sellers. Since platforms charge sellers, the revenue generated by Platform $J$ on market $i$ is $\Pi_{J i}=p_{J i} n_{s, J i}(i=\{1,2\}, J=\{A, B\})$. In the no MMC case (no multimarket platform), the objective of platform $J i$ is to maximize $\Pi_{J i}$ with respect to $p_{J i}$. In the MMC case, 
multimarket platforms consider revenue from markets 1 and 2 . In this case, Platform $\mathrm{J}(J=\{A, B\})$ maximizes $\Pi_{J}=\Pi_{J 1}+\Pi_{J 2}=p_{J 1} n_{s, J 1}+p_{J 2} n_{s, J 2}$ with respect to $p_{J 1}$ and $p_{J 2}$.

In Step 2, buyers and sellers on market 1 (resp. market 2) have to choose whether they adopt a platform or not and which platform to adopt. A type- $y$ seller joins Platform $J$ on market $i$ as long as $\pi_{J i}(y)>0$. A type- $x$ buyer chooses Platform $A i$ rather than $B i$ on market $i$ if $U_{A i}(x)>U_{B i}(x)$, with $i=\{1,2\}$.

The game is solved by backward induction assuming perfect expectations. Computations of equilibrium outcomes in the no MMC case, the MMC case with buyer-driven cross-market externality, and with seller-driven cross-market externality are presented in Appendix A.

\section{$3 \quad$ MMC impact in two-sided markets}

This section examines the impact of MMC in the context of platform competition. We compare equilibrium outcomes in a setting with two independent markets (no MMC) in which two platforms compete in each market (no MMC case) to equilibrium outcomes when two multimarket platforms compete in and serve both markets simultaneously (MMC case).

\subsection{Cross-market externalities benefit buyers}

Let first analyse the impact of MMC in the seller-driven cross-market externality setting $\left(\gamma_{b}=0\right.$, $\left.\gamma_{s}>0\right)$.

Proposition 1 When the cross-market externalities benefit buyers, platforms always charge their sellers lower access price with MMC than with no MMC.

Proof. See Appendix B

Proposition 1 departs from the mutual forbearance conjecture hypothesis, which claims that when firms meet in multiple markets, price competition is softened. This result holds in traditional (one-sided) markets, but is no longer true with two-sided markets as highlighted in Proposition 1.

This result is driven by the combined effects of cross-group and cross-market externalities. More precisely, intra-market and cross-market effects drive price competition. Consider market 1 . If a platform chooses to decrease access fees, this has a (positive) direct effect on the number of sellers 
(the paying side) and a (positive) indirect effect on the number of buyers through cross-group externalities. These intra-market effects generate a chain reaction that increases the number of sellers (paid users) using the platform and reinforce incentives to decrease price. These effects were identified by Armstrong (2006) and explain why cross-group externalities intensify price competition between platforms.

However, our framework sheds light on a second effect, namely cross-market effects. The decision of buyers to join a multimarket platform depends on the number of sellers on the other side of the platform in both markets. All other things being equal, if the platform decreases its price in market 1 , then the number of sellers on the platform in market 1 increases, which increases the utility of buyers in market 2 to choose this platform. If the platform can attract more buyers in market 2, it will also attract more sellers and generate more revenue in market 2. Hence a multimarket platform has more incentives to decrease its access fees than a single-market platform because market expansion on the seller side is greater (both markets are impacted). As a decrease in price generates additional revenue, this results in fiercer platform competition under MMC.

Proposition 2 When the cross-market externalities benefit buyers, MMC is never profitable for platforms, although they enroll more sellers.

Proof. See Appendix B

Proposition 3 When the cross-market externalities benefit buyers, buyer surplus, seller surplus and welfare are higher with $M M C$.

Proof. See Appendix B

Proposition 2 highlights an interesting paradox. Although cross-market externalities directly benefit buyers, they also indirectly benefit sellers as the access price is lower. Consequently, more sellers decide to join platforms under MMC. However, the larger number of sellers does not compensate for the lower fees and the profit of platforms decreases. Platforms are unable to capture the value of cross-market externalities. This proposition supports the claim of Evans (2017) that MMC between digital conglomerates strengthens competition and benefits platforms' users. Paradoxically, both platforms are better off in the no MMC case (i.e. in the absence of cross-market externalities). 
Since access fees decrease and platforms attract more sellers, the surpluses of buyers and sellers increase along with total welfare as stated in Proposition 3.

Platforms may be tempted to reduce or eliminate cross-market externalities $\gamma_{s}$, through contractual, technological or design choices (e.g. by preventing data sharing between platforms or by reducing service integration or interoperability). Public authorities may also influence cross-market externalities through, for example, privacy or antitrust regulation (e.g. restrictions on the collection and re-use of user data). Left and right panels of Figure 2 show the impact of seller-driven cross-market externalities on equilibrium price and platform profit respectively. They illustrate that platforms have a common interest in breaking down cross-market externalities $\gamma_{s}$ (or at least reducing their scope). From a policy perspective, restrictions on data exchange that tend to reduce the magnitude of seller-driven cross-market externalities would have a positive effect on platforms' profit and a negative effect on platform users.
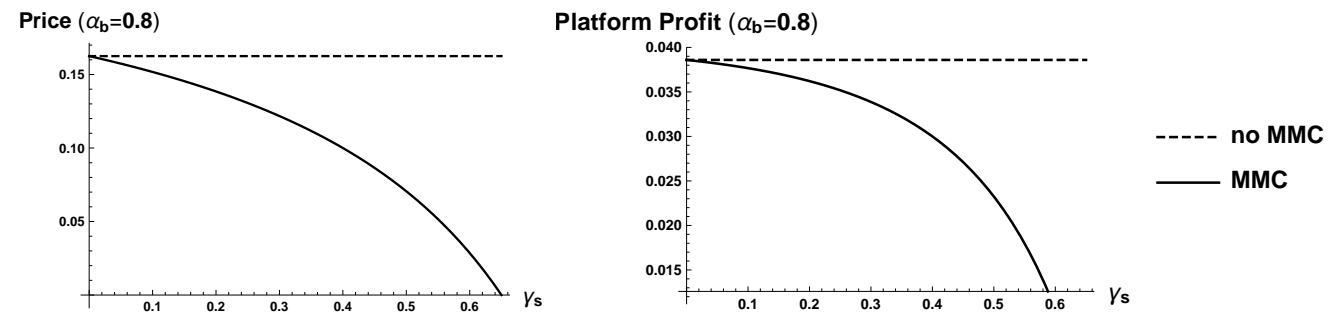

Figure 2: Relationships between equilibrium price (left) and profit (right) and the cross-market externalities with and without MMC

$$
\left(t_{b}=t_{s}=1, \alpha_{s}=0.6, \alpha_{b}=0.8, \gamma_{b}=0\right)
$$

\subsection{Cross-market externalities benefit sellers}

Let consider the case in which cross-market externality benefits the seller side $\left(\gamma_{s}=0, \gamma_{b}>0\right)$.

Proposition 4 When cross-market externalities benefit sellers, there exist two thresholds $\widetilde{\alpha}_{b, 1}$ and $\widetilde{\gamma}_{b, 1}\left(\alpha_{b}\right)$ such that platforms charge their sellers a lower price with $M M C$ unless $0<\alpha_{b}<\widetilde{\alpha}_{b, 1}$ and $0<\gamma_{b}<\widetilde{\gamma}_{b, 1}\left(\alpha_{b}\right)$. However, whatever the values of parameters, the number of sellers is always higher under $M M C$.

Proof. See Appendix B 
Proposition 1 stated that MMC has a negative impact on both price and platforms' profit regardless of the magnitude of cross-group and cross-market externalities. Proposition 4 shows that this statement does not hold if the cross-market and cross-group externalities are sufficiently low.

To explain this result, we recall that here the cross-market externality benefits the group of users (i.e. sellers) who are charged to use the platform. As previously noted, a decrease in price by a multimarket platform in market 1 generates direct and indirect intra-market effects, and intermarket effects. As the number of buyers in market 1 increases, sellers' willingness-to-pay to join this platform in market 2 increases (through $\gamma_{b}$ ). The platform may take advantage of that situation by charging a higher price. This is the case if the cross-group externalities $\left(\alpha_{b}<\widetilde{\alpha}_{b, 1}\right)$ and the crossmarket externalities $\left(\gamma_{b}<\widetilde{\gamma}_{b, 1}\right)$ are both low enough. However, if either $\gamma_{b}$ or $\alpha_{b}$ is high enough, the value of an additional buyer or seller is higher. Buyers and sellers are more sensitive to the number of users on the other side in the same market and in the other market. Competition to attract both types of users is fiercer and an increase in access fee is not a profitable strategy.

Proposition 5 When the cross-market externalities benefit sellers, there exist two thresholds $\widetilde{\alpha}_{b, 2}$ and $\widetilde{\gamma}_{b, 2}\left(\alpha_{b}\right)$ such that platforms earn lower profits with $M M C$ unless $0<\alpha_{b}<\widetilde{\alpha}_{b, 2}$ and $0<\gamma_{b}<$ $\widetilde{\gamma}_{b, 2}\left(\alpha_{b}\right)$.

\section{Proof. See Appendix B}

With low cross-group and buyer-driven cross-market externalities, we find that MMC leads to both higher prices and higher platform profits. It is only in this particular case that MMC allows platforms to relax competition. From Propositions 4 and 5, we cannot formally exclude the case in which the access price charged by the platforms decreases while their profits increase under MMC (this is more likely if cross-group and cross-market externalities are moderate).

Proposition 6 When the cross-market externalities benefit sellers, MMC is always welfare-improving and buyer surplus and seller surplus increase compared to the no-MMC situation.

\section{Proof. See Appendix B}

Proposition 6 is similar to Proposition 3. Total welfare is always higher under MMC. Even if buyers do not directly benefit from a buyer-driven cross-market externality, they capture part of it 
through higher utility (more sellers on the other side of the platform). Sellers also capture a part: more sellers join the platforms and, as previously noted, they derive a higher surplus as a whole even though access price is higher in some cases. When the cross-market externalities benefit sellers, platforms can partly appropriate some welfare gains in the case of low cross-market and cross-group externalities.

Like Figure 2, Figure 3 illustrates the impact of cross-market externalities $\left(\gamma_{b}\right)$ on platform equilibrium price and profit. Both exhibit an inverted-U shape as the cross-market externality benefits sellers. Starting with low levels of cross-market externalities, platforms have a joint incentive to enhance them since doing so enables the competitors to charge higher prices and make higher profits. However, further increases in $\gamma_{b}$ are detrimental to platforms since they generate fierce competition between them.
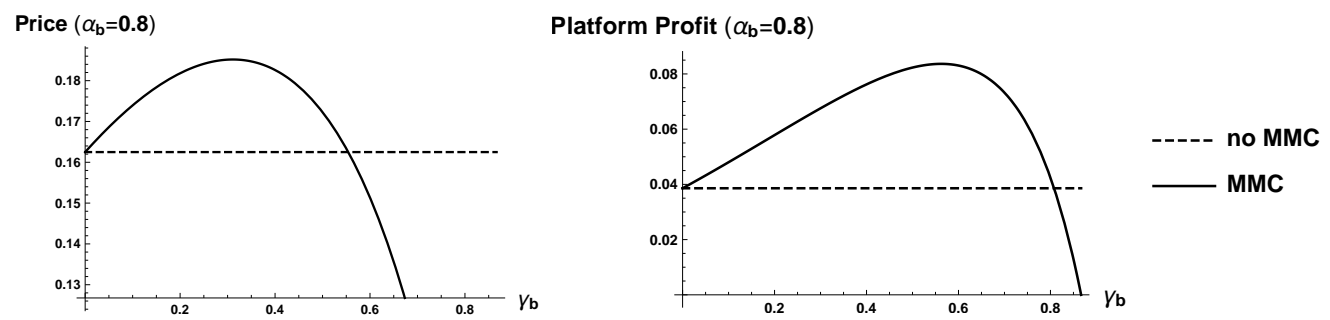

Figure 3: Relationships between equilibrium price (left) and profit (right) and the cross-market externalities with and without MMC

$$
\left(t_{b}=t_{s}=1, \alpha_{s}=0.6, \alpha_{b}=0.8, \gamma_{s}=0\right)
$$

\section{What are the incentives to become a multimarket plat- form?}

Here, we investigate the incentives for a platform owner to adopt a multimarket or conglomerate strategy. A multimarket strategy means that the firm operates a platform in both market 1 and market 2. For this purpose, we consider a setting in which only one firm is a multimarket platform and competes with single-market platforms in each market (partial MMC case). Without loss of generality, let us assume that Platform A is present in markets 1 and 2 and that B1 and B2 are two independent platforms operating in markets 1 and 2 respectively, as illustrated in Figure 4.

Compared to the MMC case, utility and profit need to be rewritten as follows: 
Partial MMC

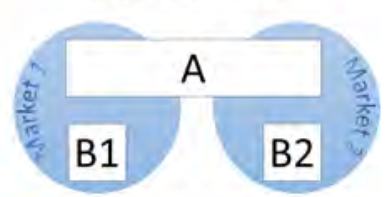

Figure 4: Partial MMC case with a multimarket platform competing with single-market platforms.

$$
\text { market i }(i=\{1,2\})\left\{\begin{array}{l}
U_{A i}(x)=v-t_{b} x+\alpha_{s} n_{s, A i}+\gamma_{\mathbf{s}} \mathbf{n}_{\mathbf{s}, \mathbf{A}-\mathbf{i}} \\
U_{B i}(x)=v-t_{b}(1-x)+\alpha_{s} n_{s, B i} \\
\pi_{A i}(y)=\alpha_{b} n_{s, A i}-t_{s} y-p_{A i}+\gamma_{\mathbf{b}} \mathbf{n}_{\mathbf{b}, \mathbf{A}-\mathbf{i}} \\
\pi_{B i}(y)=\alpha_{b} n_{s, B i}-t_{s} y-p_{B i}
\end{array}\right.
$$

In the partial MMC case, Firm A maximizes its profit in both markets with respect to $p_{A 1}$ and $p_{A 2}$. Single-market platforms $B_{i}$ maximize their profits with respect to $p_{B i}$.

Let first consider the no MMC case and examine incentives for a platform owner (say A) to adopt a multimarket strategy. In this setting, we can show that a company that competes with singlemarket platforms is always better off if it operates in two markets rather than one. For this purpose, we compare the profit level of a platform in the no MMC case to that in the partial MMC case. We find that the multimarket platform always earns a higher per market profit than a single-market platform under partial MMC. Its per market profit is also higher than that of any single-market platform under the no $\mathrm{MMC}$ case. $^{7}$ This result can be explained by the fact that a multimarket platform can attract more sellers and buyers thanks to cross-market externalities. In most cases, the multimarket platform has to reduce access fees (compared to the no-MMC case), but the decrease in price is more than compensated for by the increase in the number of sellers and overall, the profitper-market increases. Consequently, if a company expects to compete with single-market platforms, its best strategy is to implement a conglomerate strategy to obtain a competitive advantage and a larger market share on the buyers' side.

Let us now examine the strategic response of a single-market platform. Should it mimic the multimarket platform or is it best to remain a single-market platform? To answer this question, we can compare the partial MMC case to the MMC case for Platforms B1 or B2. ${ }^{8}$

\footnotetext{
${ }^{7}$ Note that this result can be analytically derived in the case of the cross-market externality benefiting buyers. Our numerical simulations obtained similar results in the case of cross-market externalities benefiting sellers. The result is true whatever the parameter values of transportation costs and externalities.

${ }^{8}$ Since this case is symmetric with respect to B1 and B2, we can study the incentive to adopt a multimarket strategy for either of the two single-market platforms.
} 
Proposition 7 When the cross-market externalities benefit buyers, there exists two thresholds $\widetilde{\alpha}_{b, 3}$ and $\widetilde{\gamma}_{b, 3}\left(\alpha_{b}\right)$ such that a single-market platform has no incentive to adopt a multimarket strategy unless $0<\alpha_{b}<\widetilde{\alpha}_{b, 3}$ and $0<\gamma_{b}<\widetilde{\gamma}_{b, 3}\left(\alpha_{b}\right)$.

Proof. See Appendix B

Proposition 8 When the cross-market externalities benefit the sellers, there exists two thresholds $\widetilde{\alpha}_{b, 4}$ and $\widetilde{\gamma}_{s, 4}\left(\alpha_{b}\right)$ such that the single-market platform has no incentive to adopt a multimarket strategy unless $0<\alpha_{b}<\widetilde{\alpha}_{b, 4}$ and $0<\gamma_{s}<\widetilde{\gamma}_{s, 4}\left(\alpha_{b}\right)$.

Proof. See Appendix B

Propositions 7 and 8 highlight a non trivial result. The intuition would rather suggest that the higher cross-market externalities, the stronger the incentive for a single-market platform to imitate the rival platform (i.e. to become a multimarket platform in turn). Such a strategy would allow the single-market platform to attract more buyers and sellers by leveraging the cross-market externality. However, we find that it is not always profit-enhancing. Propositions 7 and 8 state that a singlemarket platform is deterred from entering the second market to avoid tougher competition, when cross-group and/or cross-market externalities are sufficiently high. It implies that single-market platforms can actually coexist with a multimarket platform as a market equilibrium. In practice, it is common to find specialized platforms (e.g. Spotify) competing with conglomerate platforms (e.g. Apple music or YouTube) in digital markets.

Two points should be noted. First, the adoption of a multimarket strategy does not only depend on the magnitude of the cross-market externality, but also the cross-group externality. The two types of externalities have to be low enough to incite a single-market platform to imitate the multimarket strategy of its rival. Secondly, the conditions under which this strategy is profitable (or not) are qualitatively the same, regardless of the side that benefits from cross-market externalities.

\section{Conclusion and implications}

In this paper, we propose a theoretical framework of platform competition under MMC. We consider two markets, while firms operate a two-sided platform either in a single market or in both markets. A multimarket strategy generates a positive cross-market externality that may benefit users of the 
multimarket platform. We examine two extreme settings: the cross-market externality benefits either the group of users that pay to access the platform, or the group of users that has free access.

We highlight two types of effects that drive platform competition under MMC: i) intra-market network effects between the two sides that are connected through the platform within each market; and ii) inter-market network effects that emerge when one side of the platform in one market is connected to the other side of the platform in the second market. The first effect is common in models of platform competition (Armstrong (2006)). The second effect is unusual in the context of two-sided platforms, and refers to demand-side synergies that increase users' utility as the number of users in the other markets increases. We find that when the cross-market externality benefits the side that has free access to the platform, MMC increases competition. Platforms are unable to capture any value from cross-market externalities. When the cross-market externality benefits the side that pays, the same result holdsn, but only if the cross-group externalities (i.e. indirect network effect) and/or the cross-market externalities are sufficiently high. MMC relaxes platform competition and increases platform profits only if cross-group and cross-market externalities are sufficiently low. Finally, we show that a single-market platform that competes with a multimarket platform might prefer this asymmetric situation to avoid more intense price competition. Although a multimarket strategy will allow it to gain market share and rebalance competition, it pushes the platforms to be more aggressive regarding access fees which can be detrimental to their profits if cross-group and cross-market externalities are sufficiently large.

Our paper makes three main contributions. First we contribute to the theory of multimarket contact. The literature claims that MMC relaxes competition in traditional (one-sided) markets. We extend this literature by considering two-sided markets and find that for a large set of parameters, MMC intensifies price competition. Moreover, the range of parameters in which the mutual forbearance hypothesis still holds is rather limited (low cross-group and cross-market externalities, and sellers who benefit from cross-market externalities).

The second contribution concerns competition policy. The regulation of digital markets poses many challenges for antitrust authorities (Cremer et al. (2019)) and there is a need to better understand the multimarket strategies of tech giants (Bourreau and De Streel (2019)). Our results imply 
that antitrust authorities that have to review mergers \& acquisitions of digital platforms operating in distinct markets should first examine who is likely to benefit from cross-market externalities after platform integration. If it benefits the side that has free access to the platform, they could adopt a lenient approach because this transaction is likely to increase MMC and be welfare-enhancing for users of these digital platforms. However, if it benefits the side that pays to access the platform, authorities should be more cautious and assess the scope of cross-group and cross-market externalities. In this situation, a merger or acquisition that increases MMC may soften competition if cross-group and cross-market externalities are low enough.

Finally, our paper has managerial implications for platform-based companies. As previously noted, the timing of the adoption of a multimarket strategy is critical. The first company that commits to becoming a multimarket platform can prevent other single-market platforms from following this strategy and lock-in markets. That creates asymmetric market structure in which a multimarket platform competes with specialized platforms that have no incentive to enter other markets. This result can explain why digital conglomerates are willing to pay huge amounts to acquire specialized platforms in new markets where they are not yet active. Through this aggressive acquisition strategy, they can hinder the diversification of these emerging platforms. Our model provides also some insights into the strategic dimension of platform design. To the extent that rival platforms are able to adjust the magnitude of cross-market externalities, they have a common interest in mitigating these externalities to relax price competition (especially if these externalities benefit buyers). However, this implies that platforms have the ability to coordinate their design decisions. Such a form of collusion is outside the scope of this paper and opens new paths for future research.

\section{References}

Armstrong, M. (2006). Competition in two-sided markets. The RAND Journal of Economics, $37(3): 668$.

Behringer, S. and Filistrucchi, L. (2015). Areeda-turner in two-sided markets. Review of Industrial Organization, 46(3):287 - 306 . 
Belleflamme, P. and Peitz, M. (2019). Platform competition: Who benefits from multihoming?. International Journal of Industrial Organization, 64(2017 EARIE Proceedings):1 - 26.

Bernheim, B. D. and Whinston, M. D. (1990). Multimarket contact and collusive behavior. The RAND Journal of Economics, 21(1):1.

Bourreau, M. and De Streel, A. (2019). Digital conglomerates and eu competition policy. Technical report, SSRN Working Paper available from https://papers.ssrn.com/sol3/papers.cfm?abstract_id=3350512.

Busse, M. R. (2000). Multimarket contact and price coordination in the cellular telephone industry. Journal of Economics \&3 Management Strategy, 9(3):287 - 320.

Cabral, L., Peitz, M., Wright, J., and Belleflamme, P. (2019). Managing competition on a two-sided platform. Journal of Economics \&3 Management Strategy, 1:5.

Caillaud, B. and Jullien, B. (2003). Chicken \& egg: Competition among intermediation service providers. The RAND Journal of Economics, 34(2):309.

Correia-da Silva, J., Jullien, B., Lefouili, Y., and Pinho, J. (2019). Horizontal mergers between multisided platforms: Insights from cournot competition. Journal of Economics $\mathcal{E}$ Management Strategy, 28(1):109-124.

Cremer, J., de Montjoye, Y.-A., and Schweitzer, H. (2019). Competition policy for the digital era. Technical report, European Commission Report available from http://ec.europa.eu/competition/publications/reports/kd0419345enn.pdf.

Edwards, C. D. (1955). Conglomerate bigness as a source of power. In Business Concentration and Price Policy, pages 331-359. National Bureau of Economic Research, Inc.

Evans, D. and Noel, M. D. (2008). The analysis of mergers that involve multisided platform businesses. Journal of Competition Law and Economics, 4(3):663-695.

Evans, D. and Schmalensee, R. (2013). The antitrust analysis of multi-sided platform businesses. NBER Working Papers 18783, National Bureau of Economic Research, Inc. 
Evans, D. S. (2017). Why the dynamics of competition for online platforms leads to sleepless nights but not sleepy monopolies. Technical report, SSRN Working Paper available at SSRN: https://ssrn.com/abstract=3009438 or http://dx.doi.org/10.2139/ssrn.3009438.

Evans, W. N. and Kessides, I. N. (1994). Living by the "golden rule": Multimarket contact in the u.s. airline industry. The Quarterly Journal of Economics, 109(2):341.

Filistrucchi, L. and Klein, T. J. (2013). Price competition in two-sided markets with heterogeneous consumers and network effects. Working Papers.

Filistrucchi, L., Klein, T. J., and Michielsen, T. O. (2012). Assessing unilateral merger effects in a two-sided market: An application to the dutch daily newspaper market. Journal of Competition Law and Economics, 2:297.

Li, Z. and Agarwal, A. (2017). Platform integration and demand spillovers in complementary markets: Evidence from facebook's integration of instagram. Management Science, 63(10):34383458.

Marin, P. L. and Fernandez, N. (1998). Market power and multimarket contact: Some evidence from the spanish hotel industry. The Journal of Industrial Economics.

Parker, P. M. and Roller, L.-H. (1997). Collusive conduct in duopolies: Multimarket contact and cross-ownership in the mobile telephone industry. The RAND Journal of Economics, 28(2):304.

Peitz, M. and Valletti, T. (2015). Reassessing competition concerns in electronic communications markets. Telecommunications Policy, 39(10):896 - 912.

Phillips, O. R. and Mason, C. F. (1992). Mutual forbearance in experimental conglomerate markets. RAND Journal of Economics (RAND Journal of Economics), 23(3):395 - 414.

Prince, J. and Simon, D. H. (2009). Multimarket contact and service quality: evidence from an-time performance in the u.s. airline industry. Academy of Management Journal, 52(2):336 - 354 .

Rochet, J.-C. and Tirole, J. (2003). Platform competition in two-sided markets. Journal of the European Economic Association, 1(4):990. 
Rochet, J.-C. and Tirole, J. (2006). Two-sided markets: A progress report. The RAND Journal of Economics, 37(3):645.

Scott Morton, F., Bouvier, P., Ezrachi, A., Jullien, B., Katz, R., Kimmelman, G., Melamed, A. D., and Morgenstern, J. (2019). Committee for the study of digital platforms: Market structure and antitrust subcommittee report. Technical report, Chicago Stigler Center for the Study of the Economy and the State and University of Chicago Booth School of Business, https://research.chicagobooth.edu/-/media/research/stigler/pdfs/marketstructure - report-as-of-15-may-2019.pdf.

Shapiro, C. (2019). Protecting competition in the american economy: Merger control, tech titans, labor markets. Journal of Economic Perspectives, 33(3):69-93.

\section{Appendix}

The equilibria in the three settings (no MMC, MMC, partial MMC) are presented in Appendix A and the proofs of Propositions 1 to 8 are detailed in Appendix B. All the Wolfram Mathematica files are available upon request from the authors (as electronic supplementary material).

\section{A Equilibria}

\section{A.1 No MMC}

In the no MMC case, platforms $A 1, B 1, A 2$ and $B 2$ are independent. Equilibrium access price and market share of platform $J=\{A, B\}$ in market $i=\{1,2\}$ are given by:

$$
p_{J i}^{*}=\frac{\alpha_{b}\left(\alpha_{b} \alpha_{s}-t_{b} t_{s}\right)}{3 \alpha_{b} \alpha_{s}-4 t_{b} t_{s}}, \quad n_{b, J i}^{*}=\frac{1}{2}, \quad n_{s, J i}^{*}=\frac{1}{6} \alpha_{b}\left(\frac{2 t_{b}}{4 t_{b} t_{s}-3 \alpha_{b} \alpha_{s}}+\frac{1}{t_{s}}\right)
$$

Equilibrium profit for platform $J$ in market $i$ is

$$
\pi_{J i}^{*}=\frac{\alpha_{b}^{2}\left(\alpha_{b} \alpha_{s}-2 t_{b} t_{s}\right)\left(\alpha_{b} \alpha_{s}-t_{b} t_{s}\right)}{2 t_{s}\left(4 t_{b} t_{s}-3 \alpha_{b} \alpha_{s}\right)^{2}}
$$

Buyers' (respectively sellers') surplus in the two markets is denoted by $B S^{*}$ (respectively $S S^{*}$ ), and is given by

$$
\begin{aligned}
B S^{*} & =2\left(\frac{1}{6} \alpha_{b} \alpha_{s}\left(\frac{2 t_{b}}{4 t_{b} t_{s}-3 \alpha_{b} \alpha_{s}}+\frac{1}{t_{s}}\right)-\frac{t_{b}}{4}+v\right) \\
S S^{*} & =\frac{\alpha_{b}^{2}\left(\alpha_{b} \alpha_{s}-2 t_{b} t_{s}\right)^{2}}{2 t_{s}\left(4 t_{b} t_{s}-3 \alpha_{b} \alpha_{s}\right)^{2}}
\end{aligned}
$$

Total welfare is

$$
W^{*}=2 v+\frac{1}{18}\left(\frac{5 \alpha_{b}^{2}}{t_{s}}-\frac{4 \alpha_{b}^{2} t_{b}^{2} t_{s}}{\left(4 t_{b} t_{s}-3 \alpha_{b} \alpha_{s}\right)^{2}}+\frac{6 \alpha_{b} \alpha_{s}}{t_{s}}+\frac{8 t_{b}\left(\alpha_{b}^{2}+2 t_{b} t_{s}\right)}{4 t_{b} t_{s}-3 \alpha_{b} \alpha_{s}}-13 t_{b}\right)
$$




\section{A.2 MMC}

\section{A.2.1 MMC case when the cross-market externalities benefit buyers}

In the MMC case with seller-driven cross-market externality $\left(\gamma_{s}>0, \gamma_{b}=0\right)$, platforms $A$ and $B$ compete in both markets 1 and 2. Equilibrium access price and market share of platform $J=\{A, B\}$ in market $i=\{1,2\}$ are given by:

$$
\bar{p}_{J i}^{* *}=\frac{\alpha_{b}\left(\alpha_{b}\left(\gamma_{s}+\alpha_{s}\right)-t_{b} t_{s}\right)}{3 \alpha_{b}\left(\gamma_{s}+\alpha_{s}\right)-4 t_{b} t_{s}}, \quad \bar{n}_{b, J i}^{* *}=\frac{1}{2}, \quad \bar{n}_{s, J i}^{* *}=\frac{1}{6} \alpha_{b}\left(\frac{2 t_{b}}{4 t_{b} t_{s}-3 \alpha_{b}\left(\gamma_{s}+\alpha_{s}\right)}+\frac{1}{t_{s}}\right)
$$

The equilibrium profit for platform $J$ in market $i$ is

$$
\bar{\pi}_{J i}^{* *}=\frac{\alpha_{b}^{2}\left(\alpha_{b}\left(\gamma_{s}+\alpha_{s}\right)-2 t_{b} t_{s}\right)\left(\alpha_{b}\left(\gamma_{s}+\alpha_{s}\right)-t_{b} t_{s}\right)}{2 t_{s}\left(4 t_{b} t_{s}-3 \alpha_{b}\left(\gamma_{s}+\alpha_{s}\right)\right)^{2}}
$$

Buyers' (respectively sellers') surplus in the two markets is denoted by $\overline{B S}^{* *}$ (respectively $\overline{S S}^{* *}$ ), and is given by

$$
\begin{aligned}
\overline{B S}^{* *} & =\frac{1}{6}\left(\frac{t_{b}\left(12 t_{b} t_{s}-13 \alpha_{b}\left(\gamma_{s}+\alpha_{s}\right)\right)}{3 \alpha_{b}\left(\gamma_{s}+\alpha_{s}\right)-4 t_{b} t_{s}}+\frac{2\left(\alpha_{b}\left(\gamma_{s}+\alpha_{s}\right)+6 v t_{s}\right)}{t_{s}}\right) \\
\overline{S S}^{* *} & =\frac{\alpha_{b}^{2}\left(\alpha_{b}\left(\gamma_{s}+\alpha_{s}\right)-2 t_{b} t_{s}\right)^{2}}{2 t_{s}\left(4 t_{b} t_{s}-3 \alpha_{b}\left(\gamma_{s}+\alpha_{s}\right)\right)^{2}}
\end{aligned}
$$

Total welfare is

$\bar{W}^{* *}=2 v+\frac{1}{18}\left(\frac{\alpha_{b}\left(5 \alpha_{b}+6\left(\gamma_{s}+\alpha_{s}\right)\right)}{t_{s}}-\frac{t_{b}\left(3 \alpha_{b}^{2}\left(\gamma_{s}+\alpha_{s}\right)\left(8 \alpha_{b}+39\left(\gamma_{s}+\alpha_{s}\right)\right)-4 \alpha_{b} t_{b} t_{s}\left(7 \alpha_{b}+66\left(\gamma_{s}+\alpha_{s}\right)\right)+144 t_{b}^{2} t_{s}^{2}\right)}{\left(4 t_{b} t_{s}-3 \alpha_{b}\left(\gamma_{s}+\alpha_{s}\right)\right)^{2}}\right)$

\section{A.2.2 MMC case when the cross-market externalities benefit sellers}

In the MMC case when cross-market externality benefits sellers $\left(\gamma_{b}>0, \gamma_{s}=0\right)$, platforms $A$ and $B$ compete on both markets 1 and 2. Equilibrium access price and market share of platform $J=\{A, B\}$ in market $i=\{1,2\}$ are given by:

$$
\widehat{p}_{J i}^{* *}=\frac{\left(\alpha_{b}+\gamma_{b}\right)\left(\alpha_{s}\left(\alpha_{b}+\gamma_{b}\right)-t_{b} t_{s}\right)}{3 \alpha_{s}\left(\alpha_{b}+\gamma_{b}\right)-4 t_{b} t_{s}}, \quad \widehat{n}_{b, J i}^{* *}=\frac{1}{2}, \quad \widehat{n}_{s, J i}^{* *}=\frac{\left(\alpha_{b}+\gamma_{b}\right)\left(2 t_{b} t_{s}-\alpha_{s}\left(\alpha_{b}+\gamma_{b}\right)\right)}{8 t_{b} t_{s}^{2}-6 \alpha_{s} t_{s}\left(\alpha_{b}+\gamma_{b}\right)}
$$

The equilibrium profit for platform $J$ in market $i$ is

$$
\widehat{\pi}_{J i}^{* *}=\frac{\left(\alpha_{b}+\gamma_{b}\right)^{2}\left(\alpha_{s}\left(\alpha_{b}+\gamma_{b}\right)-2 t_{b} t_{s}\right)\left(\alpha_{s}\left(\alpha_{b}+\gamma_{b}\right)-t_{b} t_{s}\right)}{2 t_{s}\left(4 t_{b} t_{s}-3 \alpha_{s}\left(\alpha_{b}+\gamma_{b}\right)\right)^{2}}
$$

Buyers' (respectively sellers') surplus in the two markets is denoted by $\overline{B S}^{* *}$ (respectively $\overline{S S}^{* *}$ ), and is given by

$$
\begin{aligned}
\widehat{B S}^{* *} & =\frac{1}{18}\left(\frac{6 \alpha_{s}\left(\alpha_{b}+\gamma_{b}\right)}{t_{s}}+t_{b}\left(\frac{16 t_{b} t_{s}}{4 t_{b} t_{s}-3 \alpha_{s}\left(\alpha_{b}+\gamma_{b}\right)}-13\right)\right)+2 v \\
\widehat{S S}^{* *} & =\frac{\left(\alpha_{b}+\gamma_{b}\right)^{2}\left(\alpha_{s}\left(\alpha_{b}+\gamma_{b}\right)-2 t_{b} t_{s}\right)^{2}}{2 t_{s}\left(4 t_{b} t_{s}-3 \alpha_{s}\left(\alpha_{b}+\gamma_{b}\right)\right)^{2}}
\end{aligned}
$$

Total welfare is

$\widehat{W}^{* *}=2 v+$

$\frac{\alpha_{s}^{2}\left(\alpha_{b}+\gamma_{b}\right)^{3}\left(5\left(\alpha_{b}+\gamma_{b}\right)+6 \alpha_{s}\right)+4 t_{b}^{2} t_{s}^{2}\left(\alpha_{b}+\gamma_{b}\right)\left(3\left(\alpha_{b}+\gamma_{b}\right)+10 \alpha_{s}\right)-t_{b} \alpha_{s} t_{s}\left(\alpha_{b}+\gamma_{b}\right)^{2}\left(16\left(\alpha_{b}+\gamma_{b}\right)+29 \alpha_{s}\right)-16 t_{b}^{3} t_{s}^{3}}{2 t_{s}\left(4 t_{b} t_{s}-3 \alpha_{s}\left(\alpha_{b}+\gamma_{b}\right)\right)^{2}}$ 


\section{A.3 Partial MMC}

\section{A.3.1 Partial MMC when the cross-market externalities benefit buyers}

In the partial MMC case when the cross-market externality benefits buyers $\left(\gamma_{s}>0, \gamma_{b}=0\right)$, platform $A$ competes with two independent (single-market) platforms, namely platform $B 1$ in market 1 and platform $B 2$ in market 2 . The equilibrium access price and market share of platform $A$ in market $i=\{1,2\}$ are

$$
\bar{p}_{A i}^{* * *}=\frac{\alpha_{b}\left(\alpha_{b}^{3} \alpha_{s}\left(2 \alpha_{s}^{2}-\gamma_{s}^{2}\right)+2 \alpha_{b}^{2} t_{b} t_{s}\left(\gamma_{s}^{2}-6 \alpha_{s}^{2}\right)+18 \alpha_{b} t_{b}^{2} \alpha_{s} t_{s}^{2}-8 t_{b}^{3} t_{s}^{3}\right)}{\alpha_{b}^{3} \alpha_{s}\left(\alpha_{s}\left(\gamma_{s}+6 \alpha_{s}\right)-3 \gamma_{s}^{2}\right)+2 \alpha_{b}^{2} t_{b} t_{s}\left(4 \gamma_{s}^{2}-\alpha_{s}\left(\gamma_{s}+19 \alpha_{s}\right)\right)+64 \alpha_{b} t_{b}^{2} \alpha_{s} t_{s}^{2}-32 t_{b}^{3} t_{s}^{3}}
$$

and the equilibrium access price and market share of platform $B$ in market $i$ are

$$
\bar{p}_{B i}^{* * *}=\frac{\alpha_{b}\left(\alpha_{b}\left(\gamma_{s}-2 \alpha_{s}\right)+2 t_{b} t_{s}\right)\left(\alpha_{b}^{2} \alpha_{s}\left(\gamma_{s}+\alpha_{s}\right)-\alpha_{b} t_{b} t_{s}\left(3 \gamma_{s}+5 \alpha_{s}\right)+4 t_{b}^{2} t_{s}^{2}\right)}{-\alpha_{b}^{3} \alpha_{s}\left(\alpha_{s}\left(\gamma_{s}+6 \alpha_{s}\right)-3 \gamma_{s}^{2}\right)+2 \alpha_{b}^{2} t_{b} t_{s}\left(\alpha_{s}\left(\gamma_{s}+19 \alpha_{s}\right)-4 \gamma_{s}^{2}\right)-64 \alpha_{b} t_{b}^{2} \alpha_{s} t_{s}^{2}+32 t_{b}^{3} t_{s}^{3}}
$$

The equilibrium profit for platform $A$ in market $i$ is

$\bar{\pi}_{A i}^{* * *}=$

$\frac{\alpha_{b}^{2}\left(2 t_{b} t_{s}-\alpha_{b} \alpha_{s}\right)\left(\alpha_{b}^{3} \alpha_{s}\left(\gamma_{s}^{2}-2 \alpha_{s}^{2}\right)-2 \alpha_{b}^{2} t_{b} t_{s}\left(\gamma_{s}^{2}-6 \alpha_{s}^{2}\right)-18 \alpha_{b} t_{b}^{2} \alpha_{s} t_{s}^{2}+8 t_{b}^{3} t_{s}^{3}\right)^{2}}{t_{s}\left(2 t_{b} t_{s}-\alpha_{b}\left(\gamma_{s}+2 \alpha_{s}\right)\right)\left(\alpha_{b}^{3} \alpha_{s}\left(\alpha_{s}\left(\gamma_{s}+6 \alpha_{s}\right)-3 \gamma_{s}^{2}\right)+2 \alpha_{b}^{2} t_{b} t_{s}\left(4 \gamma_{s}^{2}-\alpha_{s}\left(\gamma_{s}+19 \alpha_{s}\right)\right)+64 \alpha_{b} t_{b}^{2} \alpha_{s} t_{s}^{2}-32 t_{b}^{3} t_{s}^{3}\right)^{2}}$

and the equilibrium profit for platform $B i$ in market $i$ is

$\bar{\pi}_{B i}^{* * *}=$

$\alpha_{b}^{2}\left(\alpha_{b}\left(\gamma_{s}-2 \alpha_{s}\right)+2 t_{b} t_{s}\right)\left(\alpha_{b}^{2} \alpha_{s}\left(\gamma_{s}+\alpha_{s}\right)-\alpha_{b} t_{b} t_{s}\left(3 \gamma_{s}+5 \alpha_{s}\right)+4 t_{b}^{2} t_{s}^{2}\right)^{2}\left(-\alpha_{b}^{2}\left(\gamma_{s}^{2}-2 \alpha_{s}^{2}\right)-6 \alpha_{b} t_{b} \alpha_{s} t_{s}+4 t_{b}^{2} t_{s}^{2}\right)$

$\overline{t_{s}}\left(2 t_{b} t_{s}-\alpha_{b}\left(\gamma_{s}+2 \alpha_{s}\right)\right)\left(\alpha_{b}^{3} \alpha_{s}\left(\alpha_{s}\left(\gamma_{s}+6 \alpha_{s}\right)-3 \gamma_{s}^{2}\right)+2 \alpha_{b}^{2} t_{b} t_{s}\left(4 \gamma_{s}^{2}-\alpha_{s}\left(\gamma_{s}+19 \alpha_{s}\right)\right)+64 \alpha_{b} t_{b}^{2} \alpha_{s} t_{s}^{2}-32 t_{b}^{3} t_{s}^{3}\right)^{2}$

Buyers' and sellers' surplus $\left(\overline{B S}^{* * *}\right.$ and $\left.\overline{S S}^{* * *}\right)$, as well as total welfare $\left(\bar{W}^{* * *}\right)$ are lengthy expressions. The full expressions are available upon request from the authors in a .nb Mathematica file (as supplementary material).

\section{A.3.2 Partial MMC when the cross-market externalities benefit sellers}

In the partial MMC case, when the cross-market externality benefits sellers $\left(\gamma_{b}>0, \gamma_{s}=0\right)$, platform $A$ competes with two independent platforms, namely platform $B 1$ in market 1 and platform $B 2$ in market 2 . The equilibrium access price and market share of platform $A$ in market $i=\{1,2\}$ are

$$
\widehat{p}_{A i}^{* * *}=\frac{\left(\alpha_{b}+\gamma_{b}\right)\left(\gamma_{b}^{2} \alpha_{s}^{2}\left(2 t_{b} t_{s}-\alpha_{b} \alpha_{s}\right)-2\left(t_{b} t_{s}-\alpha_{b} \alpha_{s}\right)^{2}\left(4 t_{b} t_{s}-\alpha_{b} \alpha_{s}\right)\right)}{\alpha_{b} \alpha_{s}^{3}\left(\alpha_{b} \gamma_{b}+6 \alpha_{b}^{2}-3 \gamma_{b}^{2}\right)-2 t_{b} \alpha_{s}^{2} t_{s}\left(\alpha_{b} \gamma_{b}+19 \alpha_{b}^{2}-4 \gamma_{b}^{2}\right)+64 \alpha_{b} t_{b}^{2} \alpha_{s} t_{s}^{2}-32 t_{b}^{3} t_{s}^{3}}
$$

and the equilibrium access price and market share of platform $B i$ in market $i$ are

$$
\widehat{p}_{B i}^{* * *}=-\frac{\alpha_{b}\left(\alpha_{s}\left(\gamma_{b}-2 \alpha_{b}\right)+2 t_{b} t_{s}\right)\left(\alpha_{b} \alpha_{s}^{2}\left(\alpha_{b}+\gamma_{b}\right)-t_{b} \alpha_{s} t_{s}\left(5 \alpha_{b}+3 \gamma_{b}\right)+4 t_{b}^{2} t_{s}^{2}\right)}{\alpha_{b} \alpha_{s}^{3}\left(\alpha_{b} \gamma_{b}+6 \alpha_{b}^{2}-3 \gamma_{b}^{2}\right)-2 t_{b} \alpha_{s}^{2} t_{s}\left(\alpha_{b} \gamma_{b}+19 \alpha_{b}^{2}-4 \gamma_{b}^{2}\right)+64 \alpha_{b} t_{b}^{2} \alpha_{s} t_{s}^{2}-32 t_{b}^{3} t_{s}^{3}}
$$

The equilibrium profit for platform $A$ in market $i$ is

$$
\begin{aligned}
& \widehat{\pi}_{A i}^{* * *}= \\
& \frac{2\left(\alpha_{b}+\gamma_{b}\right)^{2}\left(2 t_{b} t_{s}-\alpha_{b} \alpha_{s}\right)\left(\gamma_{b}^{2} \alpha_{s}^{2}\left(\alpha_{b} \alpha_{s}-2 t_{b} t_{s}\right)+2\left(4 t_{b} t_{s}-\alpha_{b} \alpha_{s}\right)\left(t_{b} t_{s}-\alpha_{b} \alpha_{s}\right)^{2}\right)^{2}}{t_{s}\left(2 t_{b} t_{s}-\alpha_{s}\left(2 \alpha_{b}+\gamma_{b}\right)\right)\left(\alpha_{b} \alpha_{s}^{3}\left(\alpha_{b} \gamma_{b}+6 \alpha_{b}^{2}-3 \gamma_{b}^{2}\right)-2 t_{b} \alpha_{s}^{2} t_{s}\left(\alpha_{b} \gamma_{b}+19 \alpha_{b}^{2}-4 \gamma_{b}^{2}\right)+64 \alpha_{b} t_{b}^{2} \alpha_{s} t_{s}^{2}-32 t_{b}^{3} t_{s}^{3}\right)^{2}}
\end{aligned}
$$

The equilibrium profit for platform $B i$ in market $i$ is

$$
\begin{aligned}
& \widehat{\pi}_{B i}^{* * *}= \\
& \frac{\alpha_{b}^{2}\left(\alpha_{s}\left(\gamma_{b}-2 \alpha_{b}\right)+2 t_{b} t_{s}\right)\left(\alpha_{b} \alpha_{s}^{2}\left(\alpha_{b}+\gamma_{b}\right)-t_{b} \alpha_{s} t_{s}\left(5 \alpha_{b}+3 \gamma_{b}\right)+4 t_{b}^{2} t_{s}^{2}\right)^{2}\left(\alpha_{s}^{2}\left(2 \alpha_{b}^{2}-\gamma_{b}^{2}\right)-6 \alpha_{b} t_{b} \alpha_{s} t_{s}+4 t_{b}^{2} t_{s}^{2}\right)}{t_{s}\left(2 t_{b} t_{s}-\alpha_{s}\left(2 \alpha_{b}+\gamma_{b}\right)\right)\left(\alpha_{b} \alpha_{s}^{3}\left(\alpha_{b} \gamma_{b}+6 \alpha_{b}^{2}-3 \gamma_{b}^{2}\right)-2 t_{b} \alpha_{s}^{2} t_{s}\left(\alpha_{b} \gamma_{b}+19 \alpha_{b}^{2}-4 \gamma_{b}^{2}\right)+64 \alpha_{b} t_{b}^{2} \alpha_{s} t_{s}^{2}-32 t_{b}^{3} t_{s}^{3}\right)^{2}}
\end{aligned}
$$

Similarly, buyers' and sellers' surplus $\left(\overline{B S}^{* * *}\right.$ and $\left.\overline{S S}^{* * *}\right)$, as well as welfare $\left(\bar{W}^{* * *}\right)$ are lengthy expressions. The full expressions are available upon request from the authors in a .nb Mathematica file (as supplementary material). 


\section{B Comparison of outcomes}

\section{B.1 Proof of Proposition 1}

According to assumption 1, we have $(i) t_{b} t_{s}>\alpha_{s} \alpha_{b}$ and (ii) $t_{b} t_{s}-\alpha_{b} \alpha_{s}>\gamma_{s} \alpha_{b}$. The difference between the equilibrium price of platform $J=\{A, B\}$ in market $i=\{1,2\}$, in the no-MMC case and the MMC case is given by

$$
\begin{aligned}
\Delta \bar{p}_{J i} & =\bar{p}_{J i}^{* *}-p_{J i}^{*} \\
& =\frac{\alpha_{b}\left(\alpha_{b}\left(\gamma_{s}+\alpha_{s}\right)-t_{b} t_{s}\right)}{3 \alpha_{b}\left(\gamma_{s}+\alpha_{s}\right)-4 t_{b} t_{s}}-\frac{\alpha_{b}\left(\alpha_{b} \alpha_{s}-t_{b} t_{s}\right)}{3 \alpha_{b} \alpha_{s}-4 t_{b} t_{s}} \\
& =-\frac{\gamma_{s} \alpha_{b}^{2} t_{b} t_{s}}{\left(4 t_{b} t_{s}-3 \alpha_{b} \alpha_{s}\right)\left(4 t_{b} t_{s}-3 \alpha_{b}\left(\gamma_{s}+\alpha_{s}\right)\right)}<0
\end{aligned}
$$

This proves Proposition 1.

\section{B.2 Proof of Proposition 2}

We start by proving that platforms enroll more sellers in the MMC case. For this purpose, we compute the difference between the equilibrium price of platform $J=\{A, B\}$ in market $i=\{1,2\}$ in the no-MMC case and the MMC case:

$$
\begin{aligned}
\Delta \bar{n}_{s, J i} & =\bar{n}_{s, J i}^{* *}-n_{s, J i}^{*} \\
& =\frac{1}{6} \alpha_{b}\left(\frac{2 t_{b}}{4 t_{b} t_{s}-3 \alpha_{b}\left(\gamma_{s}+\alpha_{s}\right)}+\frac{1}{t_{s}}\right)-\frac{1}{6} \alpha_{b}\left(\frac{2 t_{b}}{4 t_{b} t_{s}-3 \alpha_{b} \alpha_{s}}+\frac{1}{t_{s}}\right) \\
& =\frac{\gamma_{s} \alpha_{b}^{2} t_{b}}{\left(4 t_{b} t_{s}-3 \alpha_{b} \alpha_{s}\right)\left(4 t_{b} t_{s}-3 \alpha_{b}\left(\gamma_{s}+\alpha_{s}\right)\right)}>0
\end{aligned}
$$

We then compute the difference between the profit of platform $J=\{A, B\}$ in market $i=\{1,2\}$ in the no-MMC case and the MMC case:

$$
\begin{aligned}
\Delta \bar{\pi}_{J i} & =\bar{\pi}_{J i}^{* *}-\pi_{J i}^{*} \\
& =\frac{\alpha_{b}^{2}\left(\alpha_{b}\left(\gamma_{s}+\alpha_{s}\right)-2 t_{b} t_{s}\right)\left(\alpha_{b}\left(\gamma_{s}+\alpha_{s}\right)-t_{b} t_{s}\right)}{2 t_{s}\left(4 t_{b} t_{s}-3 \alpha_{b}\left(\gamma_{s}+\alpha_{s}\right)\right)^{2}}-\frac{\alpha_{b}^{2}\left(\alpha_{b} \alpha_{s}-2 t_{b} t_{s}\right)\left(\alpha_{b} \alpha_{s}-t_{b} t_{s}\right)}{2 t_{s}\left(4 t_{b} t_{s}-3 \alpha_{b} \alpha_{s}\right)^{2}} \\
& =\frac{\gamma_{s} \alpha_{b}^{4} t_{b}\left(3 \alpha_{b} \alpha_{s}\left(\gamma_{s}+\alpha_{s}\right)-2 t_{b} t_{s}\left(\gamma_{s}+2 \alpha_{s}\right)\right)}{2\left(4 t_{b} t_{s}-3 \alpha_{b} \alpha_{s}\right)^{2}\left(4 t_{b} t_{s}-3 \alpha_{b}\left(\gamma_{s}+\alpha_{s}\right)\right)^{2}}
\end{aligned}
$$

The sign of the expression above is given by the sign of the numerator. Since $\gamma_{s} \alpha_{b}^{4} t_{b}$ is positive, we have to examine the sign of $3 \alpha_{b} \alpha_{s}\left(\gamma_{s}+\alpha_{s}\right)-2 t_{b} t_{s}\left(\gamma_{s}+2 \alpha_{s}\right)$. As $\alpha_{b} \alpha_{s}<t_{b} t_{s}-\gamma_{s} \alpha_{b}$ (assumption 1), we can prove that this expression is always negative:

$$
\begin{aligned}
& 3 \alpha_{b} \alpha_{s}\left(\gamma_{s}+\alpha_{s}\right)-2 t_{b} t_{s}\left(\gamma_{s}+2 \alpha_{s}\right) \\
& =3 \gamma_{s} \alpha_{b} \alpha_{s}+3 \alpha_{b} \alpha_{s}^{2}-4 t_{b} \alpha_{s} t_{s}-2 \gamma_{s} t_{b} t_{s} \\
& <3 \gamma_{s} \alpha_{b} \alpha_{s}+3\left(t_{b} t_{s}-\gamma_{s} \alpha_{b}\right) \alpha_{s}-4 t_{b} t_{s} \alpha_{s}-2 \gamma_{s} t_{b} t_{s} \\
& =-2 \gamma_{s} t_{b} t_{s}-t_{b} t_{s} \alpha_{s}<0
\end{aligned}
$$

This proves Proposition 2.

\section{B.3 Proof of Proposition 3}

We start by proving that buyer surplus is larger in the MMC case than in the no-MMC case. The difference between buyer surplus in the two cases is given by

$$
\begin{aligned}
\Delta \overline{B S} & =\overline{B S}^{* *}-B S^{*} \\
& =\frac{\gamma_{s} \alpha_{b}\left(\frac{8 t_{b}^{2} t_{s}^{2}}{\left(4 t_{b} t_{s}-3 \alpha_{b} \alpha_{s}\right)\left(4 t_{b} t_{s}-3 \alpha_{b}\left(\gamma_{s}+\alpha_{s}\right)\right)}+1\right)}{3 t_{s}}
\end{aligned}
$$

Since $t_{b} t_{s}>\alpha_{s} \alpha_{b}$ and $t_{b} t_{s}-\alpha_{b} \alpha_{s}>\gamma_{s} \alpha_{b}, \Delta \overline{B S}>0$. 
We also prove that seller surplus is higher in the MMC case. The difference between seller surplus in the MMC case and the no-MMC case is given by

$$
\begin{aligned}
\Delta \overline{S S} & =\overline{S S}^{* *}-S S^{*} \\
& =\frac{2 \gamma_{s} \alpha_{b}^{3} t_{b}\left(3 \alpha_{b}^{2} \alpha_{s}\left(\gamma_{s}+\alpha_{s}\right)-5 \alpha_{b} t_{b} t_{s}\left(\gamma_{s}+2 \alpha_{s}\right)+8 t_{b}^{2} t_{s}^{2}\right)}{\left(4 t_{b} t_{s}-3 \alpha_{b} \alpha_{s}\right)^{2}\left(4 t_{b} t_{s}-3 \alpha_{b}\left(\gamma_{s}+\alpha_{s}\right)\right)^{2}}
\end{aligned}
$$

The sign of the difference is given by $g=3 \alpha_{b}^{2} \alpha_{s}\left(\gamma_{s}+\alpha_{s}\right)-5 \alpha_{b} t_{b} t_{s}\left(\gamma_{s}+2 \alpha_{s}\right)+8 t_{b}^{2} t_{s}^{2}$. It is straightforward to show that

$$
\frac{\partial g}{\partial \gamma_{s}}=\alpha_{b}\left(3 \alpha_{b} \alpha_{s}-5 t_{b} t_{s}\right)<0
$$

From Assumption 1, we obtain

$$
g>\left.g\right|_{\alpha_{s}=\frac{t_{s} t_{b}}{\alpha_{b}}-\gamma_{s}}=t_{b} t_{s}\left(3 t_{b} t_{s}-2 \alpha_{b} \alpha_{s}\right)>0
$$

This proves that seller surplus increases in the case of MMC.

The difference between total welfare in the no-MMC case and the MMC case is given by

$$
\begin{aligned}
\Delta \bar{W} & =\bar{W}^{* *}-W^{*} \\
& =\frac{1}{9}\left(\frac{3 \gamma_{s} \alpha_{b}}{t_{s}}-\frac{2 \alpha_{b}^{2} t_{b}^{2} t_{s}}{\left(4 t_{b} t_{s}-3 \alpha_{b}\left(\gamma_{s}+\alpha_{s}\right)\right)^{2}}+\frac{4 t_{b}\left(\alpha_{b}^{2}+2 t_{b} t_{s}\right)}{4 t_{b} t_{s}-3 \alpha_{b}\left(\gamma_{s}+\alpha_{s}\right)}\right. \\
& \left.+\frac{2 \alpha_{b}^{2} t_{b}^{2} t_{s}}{\left(4 t_{b} t_{s}-3 \alpha_{b} \alpha_{s}\right)^{2}}-\frac{4 t_{b}\left(\alpha_{b}^{2}+2 t_{b} t_{s}\right)}{4 t_{b} t_{s}-3 \alpha_{b} \alpha_{s}}\right)
\end{aligned}
$$

The derivative of $\Delta \bar{W}$ wrt. $\gamma_{s}$ is given by

$$
f_{1}=\frac{\partial \Delta \bar{W}}{\partial \gamma_{s}}=3 \alpha_{b}\left(-\frac{4 \alpha_{b}^{2} t_{b}^{2} t_{s}}{\left(4 t_{b} t_{s}-3 \alpha_{b}\left(\gamma_{s}+\alpha_{s}\right)\right)^{3}}+\frac{4 t_{b}\left(\alpha_{b}^{2}+2 t_{b} t_{s}\right)}{\left(4 t_{b} t_{s}-3 \alpha_{b}\left(\gamma_{s}+\alpha_{s}\right)\right)^{2}}+\frac{1}{t_{s}}\right)
$$

In order to find the sign of the derivative above, we focus on the first two terms in brackets

$$
\begin{aligned}
f_{2} & =\frac{4 t_{b}\left(\alpha_{b}^{2}+2 t_{b} t_{s}\right)}{\left(4 t_{b} t_{s}-3 \alpha_{b}\left(\gamma_{s}+\alpha_{s}\right)\right)^{2}}-\frac{4 \alpha_{b}^{2} t_{b}^{2} t_{s}}{\left(4 t_{b} t_{s}-3 \alpha_{b}\left(\gamma_{s}+\alpha_{s}\right)\right)^{3}} \\
& =\frac{4\left(-6 \gamma_{s} \alpha_{b} t_{b}^{2} t_{s}+3 \alpha_{b}^{2} t_{b}^{2} t_{s}-6 \alpha_{b} t_{b}^{2} \alpha_{s} t_{s}-3 \alpha_{b}^{3} t_{b} \alpha_{s}+8 t_{b}^{3} t_{s}^{2}-3 \gamma_{s} \alpha_{b}^{3} t_{b}\right)}{\left(-3 \gamma_{s} \alpha_{b}-3 \alpha_{b} \alpha_{s}+4 t_{b} t_{s}\right)^{3}}
\end{aligned}
$$

The sign of the denominator is negative and the sign of the numerator is given by

$$
f_{3}=-6 \gamma_{s} \alpha_{b} t_{b}^{2} t_{s}+3 \alpha_{b}^{2} t_{b}^{2} t_{s}-6 \alpha_{b} t_{b}^{2} \alpha_{s} t_{s}-3 \alpha_{b}^{3} t_{b} \alpha_{s}+8 t_{b}^{3} t_{s}^{2}-3 \gamma_{s} \alpha_{b}^{3} t_{b}
$$

Then

$$
\frac{\partial f_{3}}{\partial \alpha_{s}}=-3 \alpha_{b} t_{b}\left(\alpha_{b}^{2}+2 t_{b} t_{s}\right)<0
$$

From Assumption 1, we obtain

$$
f_{3}>\left.f_{3}\right|_{\alpha_{s}=\frac{t_{s} t_{b}}{\alpha_{b}}-\gamma_{s}}=2 t_{b}^{3} t_{s}^{2}>0
$$

Based on this, we have $f_{2}>0$, and then $f_{1}>0$. Since $\Delta W$ always increases in $\gamma_{s}$, we have

$$
\Delta \bar{W}>\left.\Delta \bar{W}\right|_{\gamma_{s}=0}=0
$$

This completes the proof. 


\section{B.4 Proof of Proposition 4}

According to assumption 2, we have $(i) t_{b} t_{s}>\alpha_{s} \alpha_{b}$ and (ii) $t_{b} t_{s}-\alpha_{b} \alpha_{s}>\gamma_{b} \alpha_{s}$. The difference between the equilibrium price of platform $J=\{A, B\}$ in market $i=\{1,2\}$, in the no-MMC case and the MMC case is given by

$$
\begin{aligned}
\Delta \widehat{p}_{J i} & =\widehat{p}_{J i}^{* *}-p_{J i}^{*} \\
& =\frac{\left(\alpha_{b}+\gamma_{b}\right)\left(\alpha_{s}\left(\alpha_{b}+\gamma_{b}\right)-t_{b} t_{s}\right)}{3 \alpha_{s}\left(\alpha_{b}+\gamma_{b}\right)-4 t_{b} t_{s}}+\frac{\alpha_{b}\left(t_{b} t_{s}-\alpha_{b} \alpha_{s}\right)}{3 \alpha_{b} \alpha_{s}-4 t_{b} t_{s}}
\end{aligned}
$$

If

$$
0<\alpha_{s}<\frac{2 t_{b} t_{s}}{3 \alpha_{b}} \text { and } 0<\gamma_{b}<\frac{-3 \alpha_{b}^{2} \alpha_{s}^{2}+8 \alpha_{b} t_{b} \alpha_{s} t_{s}-4 t_{b}^{2} t_{s}^{2}}{3 \alpha_{b} \alpha_{s}^{2}-4 t_{b} \alpha_{s} t_{s}}
$$

then it implies that $\Delta \widehat{p}_{A}>0$. Otherwise, $\Delta \widehat{p}_{A} \leq 0$. We next show that the number of sellers increases under MMC. The difference between the number of sellers on platform $J i$ in the MMC case and the no MMC case is

$$
\begin{aligned}
\Delta \widehat{n}_{s} & =\widehat{n}_{s, J i}^{* *}-n_{s, J i}^{*} \\
& =\frac{2\left(\alpha_{b}+\gamma_{b}\right)\left(2 t_{b} t_{s}-\alpha_{s}\left(\alpha_{b}+\gamma_{b}\right)\right)}{8 t_{b} t_{s}^{2}-6 \alpha_{s} t_{s}\left(\alpha_{b}+\gamma_{b}\right)}-\frac{1}{3} \alpha_{b}\left(\frac{2 t_{b}}{4 t_{b} t_{s}-3 \alpha_{b} \alpha_{s}}+\frac{1}{t_{s}}\right) \\
& =\frac{\gamma_{b}\left(\frac{8 t_{b}^{2} t_{s}^{2}}{\left(4 t_{b} t_{s}-3 \alpha_{b} \alpha_{s}\right)\left(4 t_{b} t_{s}-3 \alpha_{s}\left(\alpha_{b}+\gamma_{b}\right)\right)}+1\right)}{3 t_{s}}
\end{aligned}
$$

Since $t_{b} t_{s}>\alpha_{s} \alpha_{b}$ and $t_{b} t_{s}-\alpha_{b} \alpha_{s}>\gamma_{b} \alpha_{s}, \Delta \widehat{n}_{s}>0$, this proves Proposition 4 .

\section{B.5 Proof of Proposition 5}

Equilibrium outcomes are sometimes impossible to compare analytically. Here, this is the case when comparing the profit level of platforms $J=\{A, B\}$ in the no-MMC case and the MMC case when the cross-market externality benefits sellers. To prove Proposition 5, we run numerical simulations and use Wolfram Mathematica software to compute the profits for a large set of parameters. We follow the following procedure:

Step 1: We start by setting a value for transportation cost parameter $t_{b}$. For illustration purpose, we here normalize $t_{b}$ to 1 .

Step 2: We write a 3-loop algorithm to compare equilibrium outcomes by allowing changes in values for transportation cost parameter $t_{s}$, and cross-group externality parameters $\alpha_{b}$ and $\alpha_{s}$. We consider three possible ranges of values for the three parameters and let the cross-market externality parameter $\gamma_{k}(k=b, s)$ be constant:

- $t_{s}$ takes value in interval $[0.25 ; 4]$ with 0.25 -increment

- $\alpha_{s}$ takes value in interval $[0.1 ; 3]$ with 0.1 -increment

- $\alpha_{b}$ takes value in interval $[0.05 ; 3]$ with 0.05 -increment

Therefore, the algorithm computes 28800 comparisons and works as follows. For any parameter set $\left(t_{s}, \alpha_{s}, \alpha_{b}\right)$, we check whether the two existence conditions (see assumption 1) are satisfied, and then examine which outcome (no MMC versus MCC) is higher. If at least one of the two existence conditions is not met, the algorithm moves to the next range of parameters.

Step 3: The results of the numerical simulations allow us to establish Proposition 5.

Step 4: As robustness check, we proceed once again to Step 1 to Step 3 by choosing other values for transportation cost parameter $t_{b}$. Changing the value of transportation cost does not qualitatively modify the results stated in Proposition 5.

The comparison results are stored in several .nb files that are available upon request. 


\section{B.6 Proof of Proposition 6}

We prove Proposition 6 by showing that the sign of the difference between the welfare levels below is always positive:

$\Delta \widehat{W}$

$=\widehat{W}^{* *}-W^{*}$

$=\frac{1}{18}\left(\frac{9\left(\alpha_{s}^{2}\left(\alpha_{b}+\gamma_{b}\right)^{3}\left(5\left(\alpha_{b}+\gamma_{b}\right)+6 \alpha_{s}\right)+4 t_{b}^{2} t_{s}^{2}\left(\alpha_{b}+\gamma_{b}\right)\left(3\left(\alpha_{b}+\gamma_{b}\right)+10 \alpha_{s}\right)-t_{b} \alpha_{s} t_{s}\left(\alpha_{b}+\gamma_{b}\right)^{2}\left(16\left(\alpha_{b}+\gamma_{b}\right)+29 \alpha_{s}\right)-16 t_{b}^{3} t_{s}^{3}\right)}{t_{s}\left(4 t_{b} t_{s}-3 \alpha_{s}\left(\alpha_{b}+\gamma_{b}\right)\right)^{2}}\right.$

$\left.-\frac{5 \alpha_{b}^{2}}{t_{s}}+\frac{4 \alpha_{b}^{2} t_{b}^{2} t_{s}}{\left(4 t_{b} t_{s}-3 \alpha_{b} \alpha_{s}\right)^{2}}-\frac{6 \alpha_{b} \alpha_{s}}{t_{s}}+\frac{8 t_{b}\left(\alpha_{b}^{2}+2 t_{b} t_{s}\right)}{3 \alpha_{b} \alpha_{s}-4 t_{b} t_{s}}+13 t_{b}\right)$

The derivative of the welfare difference wrt. $\gamma_{b}$ is given by

$$
h_{1}=\frac{\partial \Delta \widehat{W}}{\partial \gamma_{s}}=\frac{\left(\begin{array}{c}
16 t_{b}^{3} t_{s}^{3}\left(3 \alpha_{b}+3 \gamma_{b}+2 \alpha_{s}\right)-8 t_{b}^{2} \alpha_{s} t_{s}^{2}\left(\alpha_{b}+\gamma_{b}\right)\left(12 \alpha_{b}+12 \gamma_{b}+7 \alpha_{s}\right) \\
4 t_{b} \alpha_{s}^{2} t_{s}\left(\alpha_{b}+\gamma_{b}\right)^{2}\left(16 \alpha_{b}+16 \gamma_{b}+9 \alpha_{s}\right)-3 \alpha_{s}^{3}\left(\alpha_{b}+\gamma_{b}\right)^{3}\left(5 \alpha_{b}+5 \gamma_{b}+3 \alpha_{s}\right)
\end{array}\right)}{t_{s}\left(4 t_{b} t_{s}-3 \alpha_{s}\left(\alpha_{b}+\gamma_{b}\right)\right)^{3}}
$$

In order to find the sign of the derivative, we focus on the numerator of the expression above. Let

$$
\begin{aligned}
h_{2} & =16 t_{b}^{3} t_{s}^{3}\left(3 \alpha_{b}+3 \gamma_{b}+2 \alpha_{s}\right)-8 t_{b}^{2} \alpha_{s} t_{s}^{2}\left(\alpha_{b}+\gamma_{b}\right)\left(12 \alpha_{b}+12 \gamma_{b}+7 \alpha_{s}\right) \\
\text { and } 3 & =4 t_{b} \alpha_{s}^{2} t_{s}\left(\alpha_{b}+\gamma_{b}\right)^{2}\left(16 \alpha_{b}+16 \gamma_{b}+9 \alpha_{s}\right)-3 \alpha_{s}^{3}\left(\alpha_{b}+\gamma_{b}\right)^{3}\left(5 \alpha_{b}+5 \gamma_{b}+3 \alpha_{s}\right)
\end{aligned}
$$

Assumption 2 implies that

$$
\begin{aligned}
h_{2} & =16 t_{b}^{3} t_{s}^{3}\left(3 \alpha_{b}+3 \gamma_{b}+2 \alpha_{s}\right)-8 t_{b}^{2} \alpha_{s} t_{s}^{2}\left(\alpha_{b}+\gamma_{b}\right)\left(12 \alpha_{b}+12 \gamma_{b}+7 \alpha_{s}\right) \\
& =8 t_{b}^{2} t_{s}^{2}\left(2 t_{b} t_{s}\left(3 \alpha_{b}+3 \gamma_{b}+2 \alpha_{s}\right)-\alpha_{s}\left(\alpha_{b}+\gamma_{b}\right)\left(12 \alpha_{b}+12 \gamma_{b}+7 \alpha_{s}\right)\right) \\
& >8\left(\alpha_{b} \alpha_{s}+\gamma_{b} \alpha_{s}\right)^{2}\left(2\left(\alpha_{b} \alpha_{s}+\gamma_{b} \alpha_{s}\right)\left(3 \alpha_{b}+3 \gamma_{b}+2 \alpha_{s}\right)-\alpha_{s}\left(\alpha_{b}+\gamma_{b}\right)\left(12 \alpha_{b}+12 \gamma_{b}+7 \alpha_{s}\right)\right) \\
& =-24 \alpha_{s}^{3}\left(\alpha_{b}+\gamma_{b}\right)^{3}\left(2 \alpha_{b}+2 \gamma_{b}+\alpha_{s}\right)
\end{aligned}
$$

and

$$
\begin{aligned}
h 3 & =4 t_{b} t_{s} \alpha_{s}^{2}\left(\alpha_{b}+\gamma_{b}\right)^{2}\left(16 \alpha_{b}+16 \gamma_{b}+9 \alpha_{s}\right)-3 \alpha_{s}^{3}\left(\alpha_{b}+\gamma_{b}\right)^{3}\left(5 \alpha_{b}+5 \gamma_{b}+3 \alpha_{s}\right) \\
& >4\left(\alpha_{b} \alpha_{s}+\gamma_{b} \alpha_{s}\right) \alpha_{s}^{2}\left(\alpha_{b}+\gamma_{b}\right)^{2}\left(16 \alpha_{b}+16 \gamma_{b}+9 \alpha_{s}\right)-3 \alpha_{s}^{3}\left(\alpha_{b}+\gamma_{b}\right)^{3}\left(5 \alpha_{b}+5 \gamma_{b}+3 \alpha_{s}\right) \\
& =\alpha_{s}^{3}\left(\alpha_{b}+\gamma_{b}\right)^{3}\left(49 \alpha_{b}+49 \gamma_{b}+27 \alpha_{s}\right)
\end{aligned}
$$

Therefore we have

$$
\begin{aligned}
h 2+h 3 & >-24 \alpha_{s}^{3}\left(\alpha_{b}+\gamma_{b}\right)^{3}\left(2 \alpha_{b}+2 \gamma_{b}+\alpha_{s}\right)+\alpha_{s}^{3}\left(\alpha_{b}+\gamma_{b}\right)^{3}\left(49 \alpha_{b}+49 \gamma_{b}+27 \alpha_{s}\right) \\
& =\alpha_{s}^{3}\left(\alpha_{b}+\gamma_{b}\right)^{3}\left(\alpha_{b}+\gamma_{b}+3 \alpha_{s}\right) \\
& >0
\end{aligned}
$$

We can conclude that $h_{1}>0$, which implies that $\Delta \widehat{W}$ always increases in $\gamma_{b}$, and consequently,

$$
\Delta \widehat{W}>\left.\Delta \widehat{W}\right|_{\gamma_{b}=0}=0
$$

This completes the proof.

\section{B.7 Proof of Proposition 7}

Just like for the proof of Proposition 5, we cannot analytically compare the profit levels because of the complexity of the expressions of equilibrium profits. Therefore, we compare profit levels using the same procedure as that used in Proposition 5. The proof of Proposition 7 is available in a Mathematica .nb file.

\section{B.8 Proof of Proposition 8}

As for the proofs of Proposition 5 and 7, we cannot analytically compare the profit levels because of the complexity of the expressions of equilibrium profits. Consequently we use simulations through Wolfram Mathematica. The proof of Proposition 8 is provided in a Mathematica .nb file in which different outcomes are computed for a set of parameters and then compared, following the same procedure than that described in the proof of Proposition 5. 